\title{
Stereoconvergent and -divergent Synthesis of Tetrasubstituted Al- kenes by Nickel-Catalyzed Cross-Couplings
}

\author{
Daniel Zell, ${ }^{\S *}$ Cian Kingston, ${ }^{\nabla \dagger}$ Janis Jermaks, ${ }^{\S}$ Sleight R. Smith, ${ }^{\nabla}$ Natalie Seeger, ${ }^{\nabla}$ Jana Wassmer, ${ }^{\S}$ \\ Lauren E. Sirois, ${ }^{\S}$ Chong Han, ${ }^{\S}$ Haiming Zhang, ${ }^{\S}$ Matthew S. Sigman ${ }^{*}$ and Francis Gosselin ${ }^{\S}$ \\ $\S$ Department of Small Molecule Process Chemistry, Genentech, Inc., 1 DNA Way, South San Francisco, California 94080, \\ United States \\ $\nabla$ Department of Chemistry, University of Utah, Salt Lake City, Utah 84112, United States
}

\begin{abstract}
We report the development of a method to diastereoselectively access tetrasubstituted alkenes via nickel-catalyzed Suzuki-Miyaura cross-couplings of enol tosylates and boronic acid esters. Either diastereomeric product was selectively accessed from a mixture of enol tosylate starting material diastereomers in a convergent reaction by judicious choice of the ligand and reaction conditions. A similar protocol also enabled a divergent synthesis of each product isomer from diastereomerically pure enol tosylates. Notably, high-throughput optimization of the monophosphine ligands was guided by chemical space analysis of the kraken library to ensure a diverse selection of ligands was examined. Stereoelectronic analysis of the results provided insight into the requirements for reactive and selective ligands in this transformation. The synthetic utility of the optimized catalytic system was then probed in the stereoselective synthesis of various tetrasubstituted alkenes, with yields up to 94\% and diastereomeric ratios up to 99:1 Z/E and 93:7 $E / Z$ observed. Moreover, a detailed computational analysis and experimental mechanistic studies provided key insights into the nature of the underlying isomerization process impacting selectivity in the cross-coupling.
\end{abstract}

\section{Introduction}

Molecules with all-carbon tetrasubstituted alkene structural motifs, such as the estrogen receptor modulators tamoxifen and idoxifene, ${ }^{1-4}$ amongst others (Figure 1A), have displayed significant biological activity and found widespread applications in the pharmaceutical industry. ${ }^{5-9}$ Moreover, their unique photoand electrochemical properties have rendered them particularly useful for molecular switches ${ }^{10-11}$ and material science. ${ }^{12-14}$ Despite this rising demand, the stereoselective synthesis of tetrasubstituted alkenes has been a longstanding challenge and as a result only a few synthetic approaches have been reported in recent years. ${ }^{15-19}$ While key progress in this field has been achieved by employing traditional olefination methods, these transformations often suffer from low atom-economy and poor stereoselectivity. ${ }^{20-23}$ One of the most commonly applied synthetic strategies is the carbometalation of internal alkynes, followed by a metal-catalyzed cross-coupling. ${ }^{24-28}$ This elegant approach has set the stage for a plethora of useful tetrasubstituted alkene syntheses, but is often associated with serious limitations regarding stereocontrol and functional group tolerance. In addition to the utilization of oxidative Heck couplings, ${ }^{29-34}$ more recent examples have showcased that cross-couplings of tetrasubstituted alkenyl electrophiles comprise an attractive alternative to tradition alkene coupling reactions. However, a vast majority of these transformations are structurally limited to $\alpha, \beta$-unsaturated compounds, such as acrylates and ketones. ${ }^{34-42}$

In contrast, highly stereoselective methods for the assembly of unactivated acyclic tetrasubstituted alkenes have remained scarce. In 2017, our group reported a two-step synthesis of tetrasubstituted alkenes, in which the stereochemical outcome is set by diastereoselective preparation of the enol tosylate starting material, followed by a stereoretentive Pd-catalyzed Suzuki-Miyaura cross-coupling (Figure 1B). ${ }^{43}$ Although this protocol allowed for the highly selective synthesis of $(E)$-alkenes, the selectivity was largely governed by the tosylation step and ultimately limited access to $(Z)$-alkenes, whose precursor tosylates were less accessible in high diastereomeric purity.

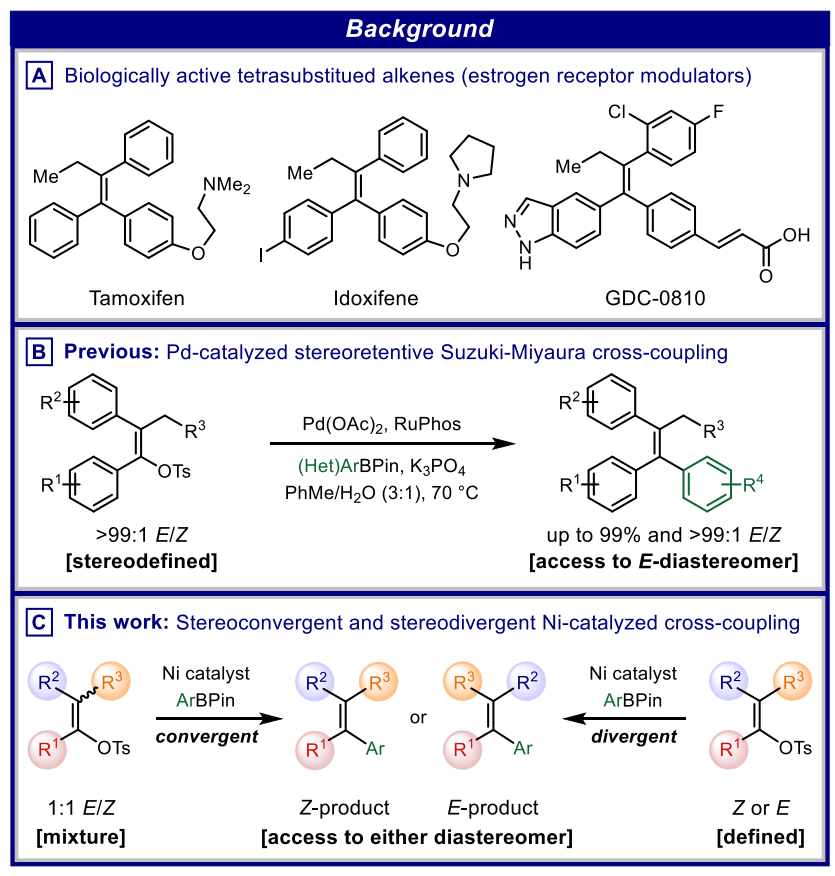


Figure 1. (A) Selected examples of stereodefined tetrasubstituted alkenes in drug molecules. (B) Stereoretentive Pd-catalyzed crosscoupling. (C) Diastereoconvergent and -divergent Ni-catalyzedcross-coupling.

Capitalizing on seminal studies of stereodivergent $\mathrm{Pd}$-catalyzed cross-couplings of disubstituted alkenyl halides by Lipshutz, ${ }^{44}$ ${ }^{46}$ we set out to develop a stereoselective cross-coupling reaction that does not rely on the geometry of the starting material and gives expedient access to stereodefined tetrasubstituted alkene products.

Herein, we report a ligand-controlled Ni-catalyzed synthesis of stereodefined tetrasubstituted alkenes from either a single enol tosylate diastereomer in a stereodivergent process, or, alternatively, from a diastereomeric mixture of starting materials in a stereoconvergent manner (Figure 1C). It is important to note that either product diastereomer can be generated under the stereodivergent/-convergent regimes by simply switching the ligand and solvent system. The diastereo-convergent reaction is highlighted in this report due to its synthetic utility, as it obviates the need for stereoselective starting material preparation, which is particularly challenging for the corresponding $(Z)$-configured enol tosylates. ${ }^{47}$ An optimization study was designed ${ }^{48-}$ ${ }^{52}$ by using kraken, a computational database of $>1500$ phosphorus ligand descriptors, to identify a diverse set of phosphines to evaluate, which enabled the identification of reaction conditions for Ni-catalyzed Suzuki-Miyaura cross-coupling. ${ }^{53-}$ ${ }^{55}$ The optimized conditions were then applied to the synthesis of a variety of tetrasubstituted alkene scaffolds in typically high diastereomeric ratios of up to $\sim 90: 10 E / Z$ and $Z / E$. Notably, the unique mechanistic features of this catalytic transformation contrast the thermodynamic control of previously developed convergent cross-couplings for the synthesis of di- and trisubstituted alkenes, which typically proceed via metal-hydride catalyzed isomerizations. ${ }^{56-58}$ Our mechanistic hypothesis is supported by a combination of DFT calculations and experimental insights to shed insight into the elusive isomerization step that has previously been observed in several cross-coupling reactions of alkenyl electrophiles. ${ }^{46,53,59}$

\section{Results and Discussion}

Optimization Studies. At the outset of the investigation, preliminary experimental data indicated that monophosphine ligands effectively promoted a nickel $(0)$ cross-coupling of enol tosylate $\mathbf{1 a}$ and pinacol boronate $\mathbf{2 a}$ to access representative tetrasubstituted alkene diastereomers 3aa (Figure 2A, see SI for details). To further streamline efforts toward developing a ligand-controlled diastereoconvergent transformation, a datarich optimization approach was envisaged wherein chemical space analysis would guide high throughput experimentation (HTE). ${ }^{60-61}$ The kraken organophosphorus(III) descriptor library, which contains $>190$ conformationally relevant molecular descriptors for 1558 monodentate phosphorus ligands, was employed for this purpose (Figure $2 \mathrm{~B}$ ). ${ }^{62}$ The dimensionality of the descriptors for commercially available phosphine ligands within the library was reduced using principal component analysis. ${ }^{63} \mathrm{~K}$-means clustering was applied to the resulting chemical space in order to facilitate the selection of 47 diverse ligands for HTE optimization. Ligands were selected from each of these clusters based on availability in our library as well as further curation for compatibility with the reaction conditions. Subsequently, a $\sim 50: 50$ mixture of enol tosylate diastereomers $(Z)$ $\mathbf{1 a} /(E)-\mathbf{1 a}$ was subjected to reaction with boronate $\mathbf{2 a}$ under the established baseline conditions (Ni(COD) ${ }_{2}, \mathrm{~K}_{3} \mathrm{PO}_{4}$, THF/water (3:1)) with the 47 selected monophosphine ligands in a 96-well plate design (reactions were performed in duplicate, and both assay yield and $E / Z$ ratio was determined for product 3aa in each case; see SI for details). Wide ranges of both reactivity and selectivity were observed, thereby validating the efficacy of the workflow for identification of a diverse ligand screening set.

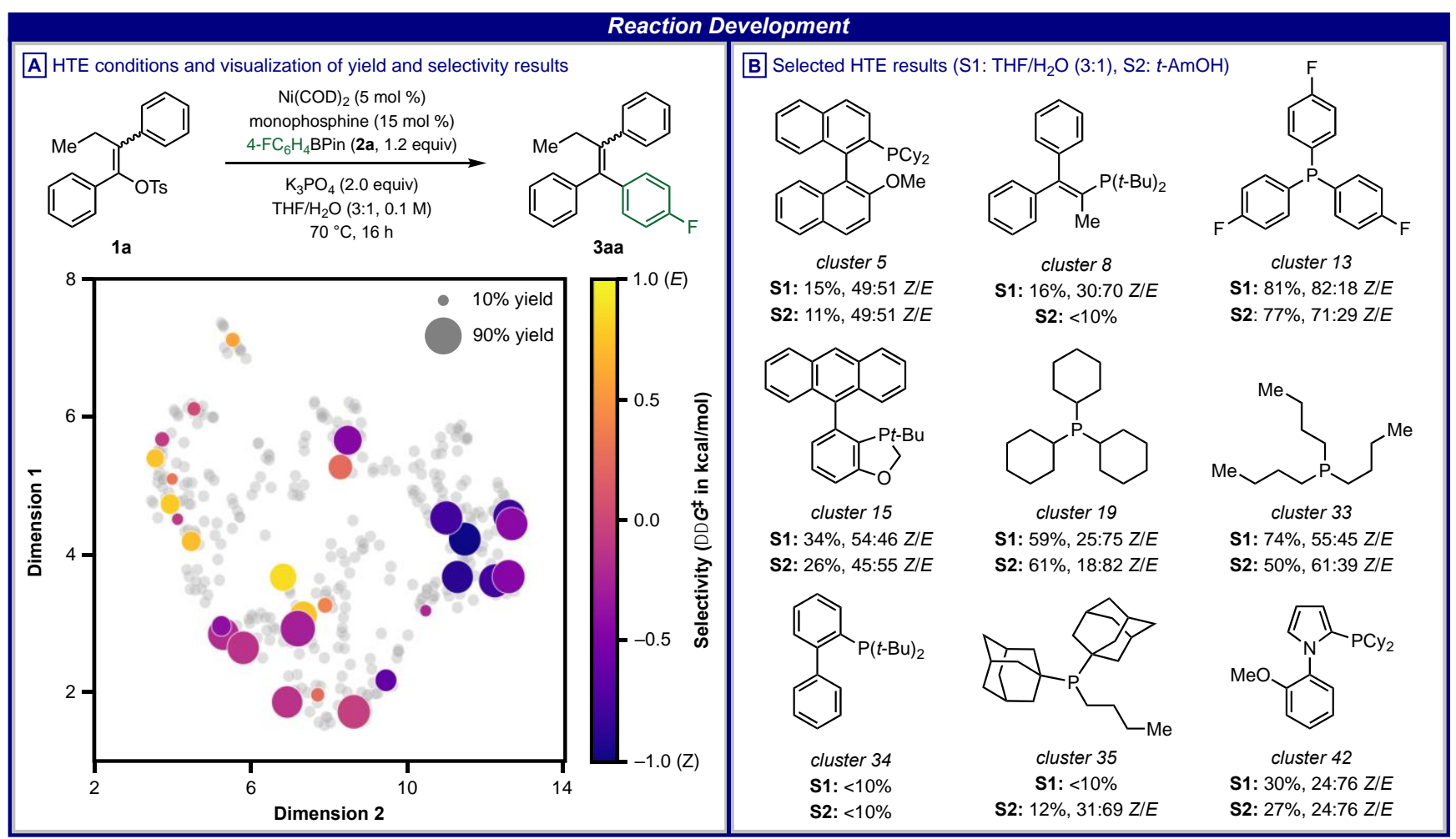


Figure 2. (A) Conditions for HTE and visualization of the ligand chemical space and HTE yield and selectivity results. (B) Selected examples from the HTE results for the formation of 3aa.

The selection of ligands from the kraken library was visualized using the non-linear dimensionality reduction technique Uniform Manifold Approximation and Projection (UMAP), which showed reasonably even coverage of the commercially available phosphine space in this projection (Figure 2A). ${ }^{64-65}$ The selectivity observed with each ligand is highlighted on the UMAP plot through the use of a color map, while the size of the point represents the observed yield. A clear region of higher $(Z)$-selectivity for alkene 3aa was observed in the eastern area of the ligand space, while the highest $(E)$-selectivity were observed in the central and western areas of the plot. In addition, $(Z)$-selective ligands were generally higher yielding than the $(E)$-selective ligands. In a few cases, multiple ligands from the same cluster were probed in order to test the hypothesis that monophosphines in the same regions of chemical space will react similarly and in general, similar reactivities and selectivities were observed (see SI for details). The same HTE screen was also repeated in $t-\mathrm{AmOH}$ in order to test the effect of solvent on the reaction. Representative HTE results are highlighted in Figure $2 \mathrm{~B}$. In general, the ligand had the most significant influence on selectivity and similar trends were observed in either solvent. Ultimately, $\mathrm{P}\left(4-\mathrm{FC}_{6} \mathrm{H}_{4}\right)_{3}(\mathbf{L 1})$ in $\mathrm{THF} / \mathrm{H}_{2} \mathrm{O}$ (3:1) and $\mathrm{PCy}_{3}$ (L2) in $t$-AmOH provided the highest yield and selectivity for each product diastereomer $(Z)-3 \mathbf{a a}$ and $(E)-\mathbf{3 a a}$, respectively (Figure $2 \mathrm{~B}) . \mathrm{PCy}_{3}(\mathbf{L 2})$ has proven effective several Ni-catalyzed Suzuki-Miyaura cross-coupling reactions. ${ }^{66-68}$ Further optimization studies indicated a $\mathrm{THF} / \mathrm{H}_{2} \mathrm{O}$ ratio of $4: 1$ to be slightly more effective for the (Z)-selective conditions (see SI for details). Similar trends in reactivity and selectivity were also observed upon performing the ligand HTE screen with two additional electronically differentiated enol tosylate substrates, thereby ensuring the optimized conditions were not limited to $1 a$ (see SI for details).

In addition to facilitating the identification of highly selective ligands, a diverse coverage of chemical space provides a platform to analyze correlations between descriptors and reaction outcomes. The molecular electrostatic potential minimum $\left(V_{\min }\right)$ in the phosphorus lone pair region is a quantitative measure of the $\sigma$-donating ability of a phosphine ligand, and was therefore chosen as a suitable electronic descriptor (Figure 3A). ${ }^{69}$ More specifically, Boltzmann-averaged $V_{\min }$ values from the collection of ligand conformers in the kraken library were used $\left(V_{\min }(\right.$ Boltz)). Regarding steric effects, buried volume $\left(V_{\text {bur }}\right)$ is defined as the total volume of a sphere that is occupied by the substituents of the ligand (in this case, the sphere is centered on the phosphorus atom with a radius of $3.5 \AA) .{ }^{70-71}$ Furthermore, the minimum buried volume $\left(V_{\text {bur }}(\mathrm{min})\right)$ is the smallest possible value of $V_{\text {bur }}$ for energetically accessible conformers of the ligand. Hence, $V_{\text {bur }}$ ( $\mathrm{min}$ ) quantifies the lowest proximal steric bulk associated with a ligand and was recently applied as a readout of ligation state in Pd- and Ni-catalyzed crosscouplings. ${ }^{72}$ Visualization of the stereoelectronic space was performed by plotting the ligands using the two aforementioned descriptors and coloring the points by reaction output. A single productive region of ligand space was observed for high reactivity with $V_{\min }$ (Boltz) values from -0.062 to $-0.038 \mathrm{~V}$ and $V_{\text {bur }}$ (min) values from 42 to $50 \AA^{3}$ (Figure $3 \mathrm{~B}$, orange box). Two distinct regions were apparent for either high $(E)$ - or high $(Z)$ selectivity (Figure 3C, red and blue boxes), separated electronically at roughly $-0.058 \mathrm{~V}$, with electron deficient phosphines displaying greater $(Z)$-selectivity and vice versa.

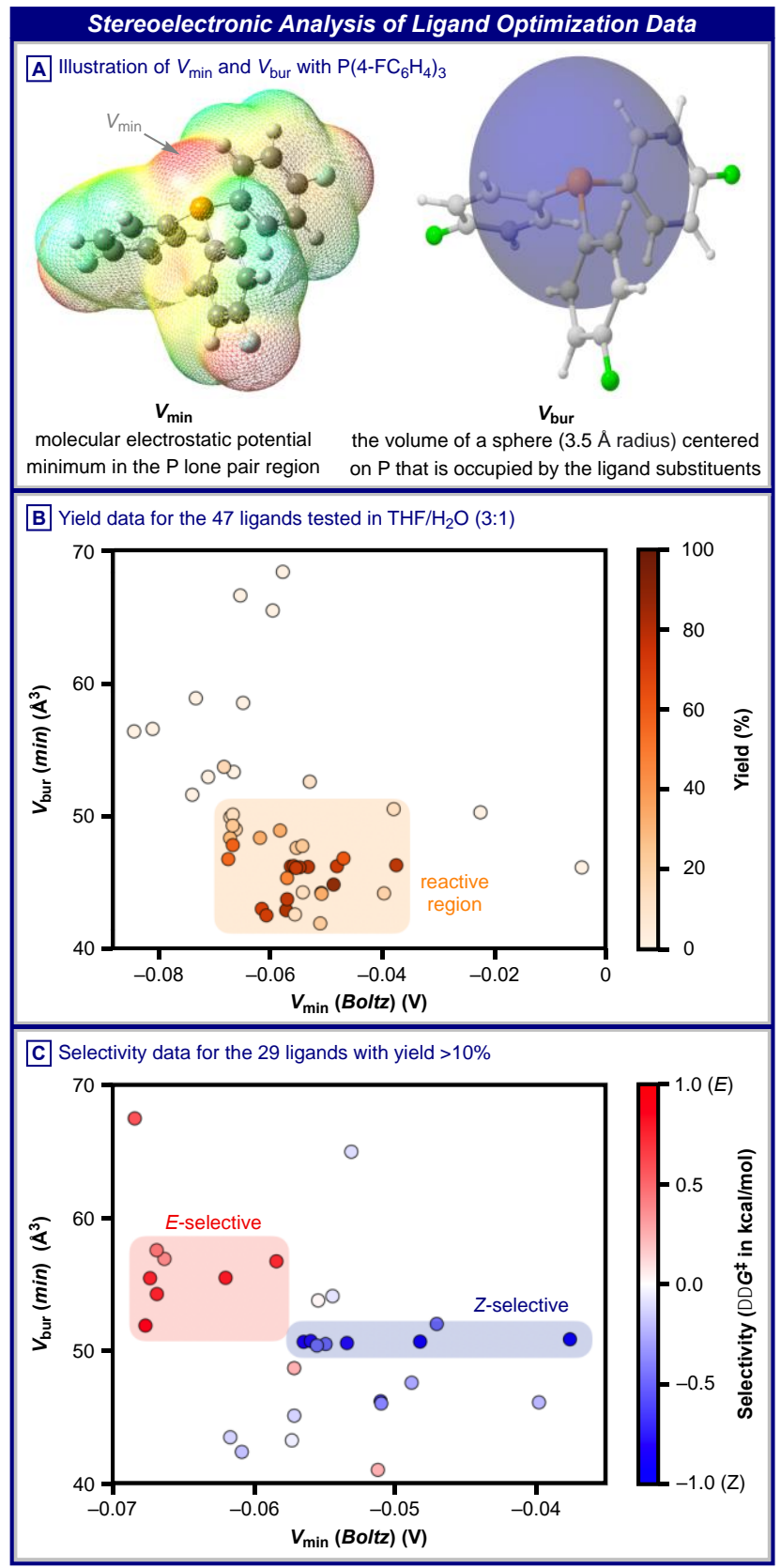

Figure 3. (A) Illustration of $V_{\min }$ and $V_{\text {bur. }}(\mathrm{B}, \mathrm{C})$ Analysis of the HTE yield and selectivity results.

Regarding $V_{\text {bur }}$ ( $\mathrm{min}$ ), the two selectivity regions were separated at $\sim 52 \AA^{3}$, which is a value that generally distinguished between mono- and bis-ligated $\mathrm{Ni}$-complexes in a recent study reported by Sigman and Doyle. ${ }^{72}$ However, further investigation would be required to confirm the influence of ligation state on selectivity in this transformation.

The aggregate data from the HTE screen also provided the opportunity to predict more selective monophosphines from the kraken library. To identify ligands for a highly (Z)-selective process, potential phosphines were initially filtered using the descriptor values that defined the reactive region of chemical space (Figure 3B, orange box). Thereafter, the HTE selectivity data was employed to develop an ensemble of multivariable linear regression models that were used to virtually screen the remaining phosphines (see SI for details). Both $\mathrm{P}\left(4-\mathrm{ClC}_{6} \mathrm{H}_{4}\right)_{3}$ and 
$\mathrm{PPh}_{2}\left(4-\mathrm{CO}_{2} \mathrm{HC}_{6} \mathrm{H}_{4}\right)$ were predicted to be marginally more (Z)selective than L1 (Figure 4). However, the ligands were found to be less reactive (presumably due to chemoselectivity issues) and slightly less selective than $\mathbf{L 1}$ upon experimental validation.

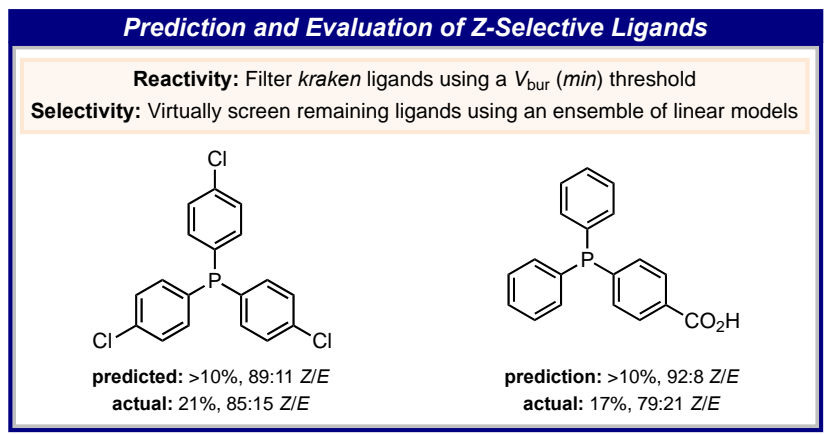

Figure 4. Prediction of more $(Z)$-selective ligands.

Substrate Scope. With optimized conditions in hand, we sought to probe the efficiency and selectivity of both $(E)$ - and $(Z)$-selective catalytic reaction regimes on a variety of different enol tosylates 1. To this end, 50:50 mixtures of the enol tosylate diastereomers $(E / Z)-1$ were subjected to both optimized protocols ( $\mathbf{L 1}$ in THF/ $\mathrm{H}_{2} \mathrm{O}(4: 1)(\mathbf{C 1})$ or $\mathbf{L 2}$ in $\left.t-\mathrm{AmOH}(\mathbf{C 2})\right)$ with pinacol boronate $\mathbf{2 a}$ as the coupling partner (Scheme 1). Switching the conditions in such a way provided selective access to either diastereomeric tetrasubstituted alkene products $(E)$ - and $(Z)-3$. In order to obtain potentially mechanistically relevant data from this substrate scope, the enol tosylate starting material 1 was geometrically divided into quadrants and stereoelectronically diverse substituents were explored for each.

Generally, we were pleased to find that the desired ligand-modulated switch in diastereoselectivity was achieved for the examples evaluated. Thus, the diastereomeric product ratios typically ranged between 80:20-90:10 E/Z or $Z / E$, accordingly, with only minor exceptions. The same observation was made in terms of isolated combined yields of both product diastereomers, which were mostly between $70-90 \%$ and showed minimal dependence on the corresponding reaction conditions C1 versus C2. Notably, a substituent variation in the northwestern enol tosylate quadrant from ethyl (3a) to methyl (3b) and isopropyl (3c) led to a reduction in $(Z)$-diastereoselectivity from $86: 14$ (3aa) to 58:42 (for 3ba) and 68:32 Z/E (for 3ca). In contrast, there was no noticeable difference in selectivity or yield upon evaluating different substituents in the northeastern quadrant (products 3ea-3ha).

Scheme 1. Scope of enol tosylates in the Ni-catalyzed stereoconvergent Suzuki-Miyaura coupling. ${ }^{a}$

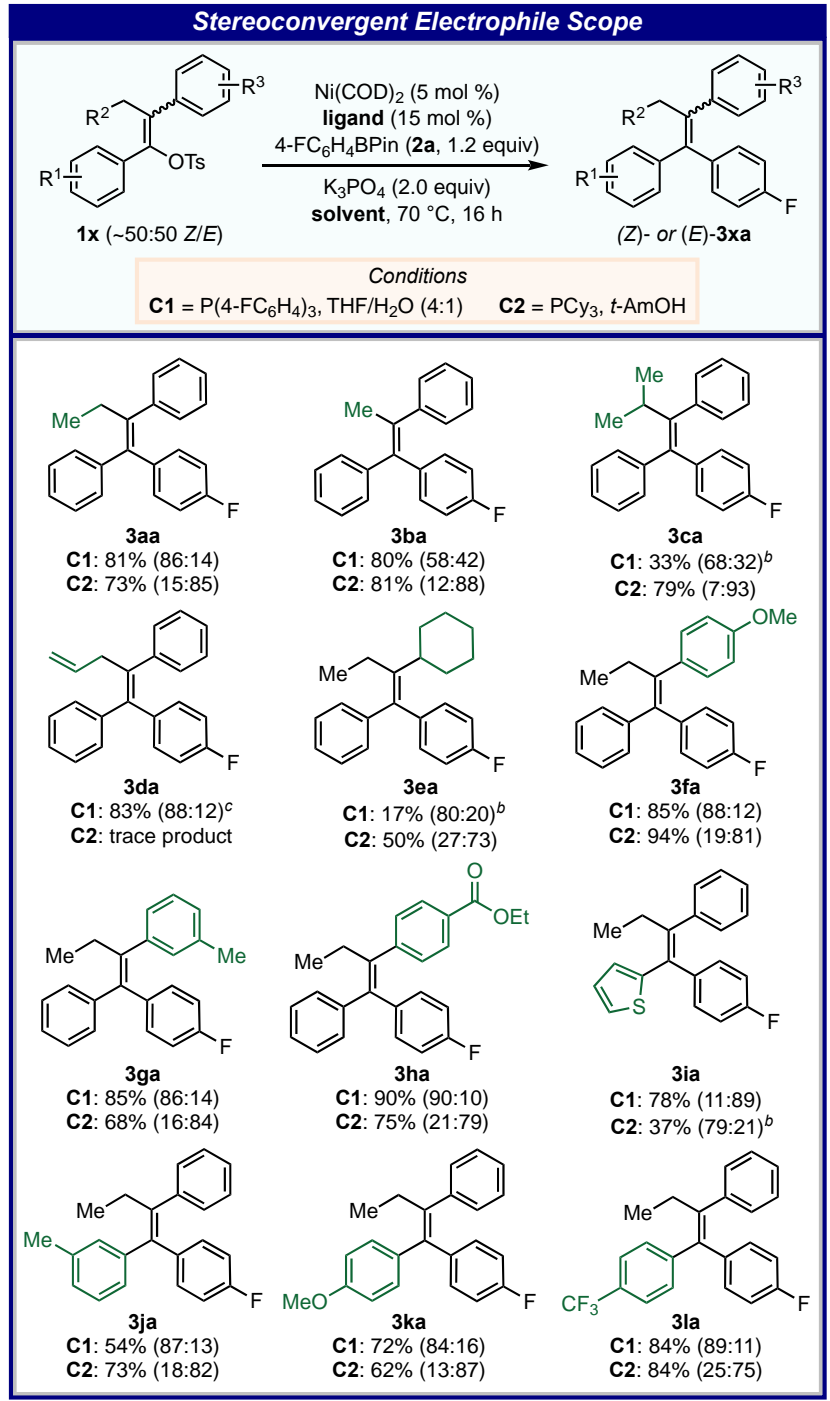

${ }^{a}$ Combined isolated yields; $(Z / E)$-diastereomeric ratio of product shown in parentheses. Reaction conditions C1: $(E / Z)-\mathbf{1}(0.25 \mathrm{mmol}$ each, 1.0 equiv), 2a (1.2 equiv), $\mathrm{Ni}(\mathrm{COD})_{2}(5.0 \mathrm{~mol} \%), \mathbf{L 1}(15 \mathrm{~mol} \%), \mathrm{K}_{3} \mathrm{PO}_{4}$ (2.0 equiv), $70{ }^{\circ} \mathrm{C}, \mathrm{THF} / \mathrm{H}_{2} \mathrm{O}(4: 1,0.33 \mathrm{M}), 16 \mathrm{~h}$. Conditions C2: $(E / Z)-\mathbf{1}(0.25 \mathrm{mmol}$ each, 1.0 equiv), 2a (1.2 equiv), $\mathrm{Ni}(\mathrm{COD})_{2}(5.0 \mathrm{~mol} \%)$, $\mathbf{L 2}(15 \mathrm{~mol} \%)$, $70{ }^{\circ} \mathrm{C}, t-\mathrm{AmOH}(0.33 \mathrm{M}), 16 \mathrm{~h} .{ }^{b}$ Using $\mathrm{K}_{3} \mathrm{PO}_{4}(1.0$ equiv), $2 \mathrm{a}$ (3.0 equiv), $\mathrm{Ni}(\mathrm{COD})_{2}(10 \mathrm{~mol} \%), \mathbf{L 1}$ or $\mathbf{L} 2(30 \mathrm{~mol} \%) .{ }^{c}$ Using $\mathrm{K}_{3} \mathrm{PO}_{4}$ (2.0 equiv), 2a (2.0 equiv), $\mathrm{Ni}(\mathrm{COD})_{2}(10 \mathrm{~mol} \%), \mathbf{L} 1$ or $\mathbf{L 2}(30 \mathrm{~mol} \%)$.

Importantly, the sterically encumbered cyclohexyl-substituted alkene product 3ea was accessed with the same switch in diastereoselectivity from 80:20 (using conditions C1) to 27:73 Z/E (using C2), indicating that our method is applicable to scaffolds that are not only derived from stilbene. The reduction in yield, especially for the $(Z)$-selective conditions, could be attributed to steric interactions with the bulky cyclohexyl group. Variation of para-substituents on the southwestern quadrant of $\mathbf{1}$ showed the subtle effect of electronic features on selectivity, in that a lower $(E)$-selectivity was observed for $p-\mathrm{CF}_{3}$ (product 3la, 75:25 $E / Z)$ than for $p$-OMe (3ka, 87:13 E/Z) while the $(Z)$-selectivity remained relatively consistent (3la, 89:11 Z/E and 84:16 Z/E for 3ka).

After showcasing the consistent performance of this protocol in the reactions of diversely substituted enol tosylates $\mathbf{1}$ with pinacol boronate $\mathbf{2 a}$, we turned our focus to evaluating the effect of different cross-coupling nucleophiles (Scheme 2). Electronically varied substituents in the para-position of phenyl-substi- 
tuted pinacol boronates 2 did not affect the diastereoselectivities for 3ab or 3ac significantly, with $\sim 85: 15 E / Z$ and $Z / E$ observed consistently using conditions $\mathbf{C} 2$ or $\mathbf{C 1}$, respectively. It is noteworthy that both diastereomers of tamoxifen (3ad) were produced in good yields and high selectivities, thereby avoiding a stereoselective starting material synthesis ${ }^{73}$ and rendering our approach orthogonal and more functional group tolerant than those previously employing carbolithiation/cross-coupling synthetic strategies. ${ }^{26-27,74}$ Moreover, a gram-scale synthesis of (Z)tamoxifen performed well with $82 \%$ yield and 86:14 Z/E. An ortho-methyl substituent (giving product 3ae) was well tolerated under $(Z)$-selective $\mathbf{C 1}$ conditions, with slightly diminished yield and selectivity under $(E)$-selective conditions $\mathbf{C 2}$.

Scheme 2. Scope of nucleophiles in Ni-catalyzed stereoconvergent cross-couplings with enol tosylate $1 a^{a}{ }^{a}$

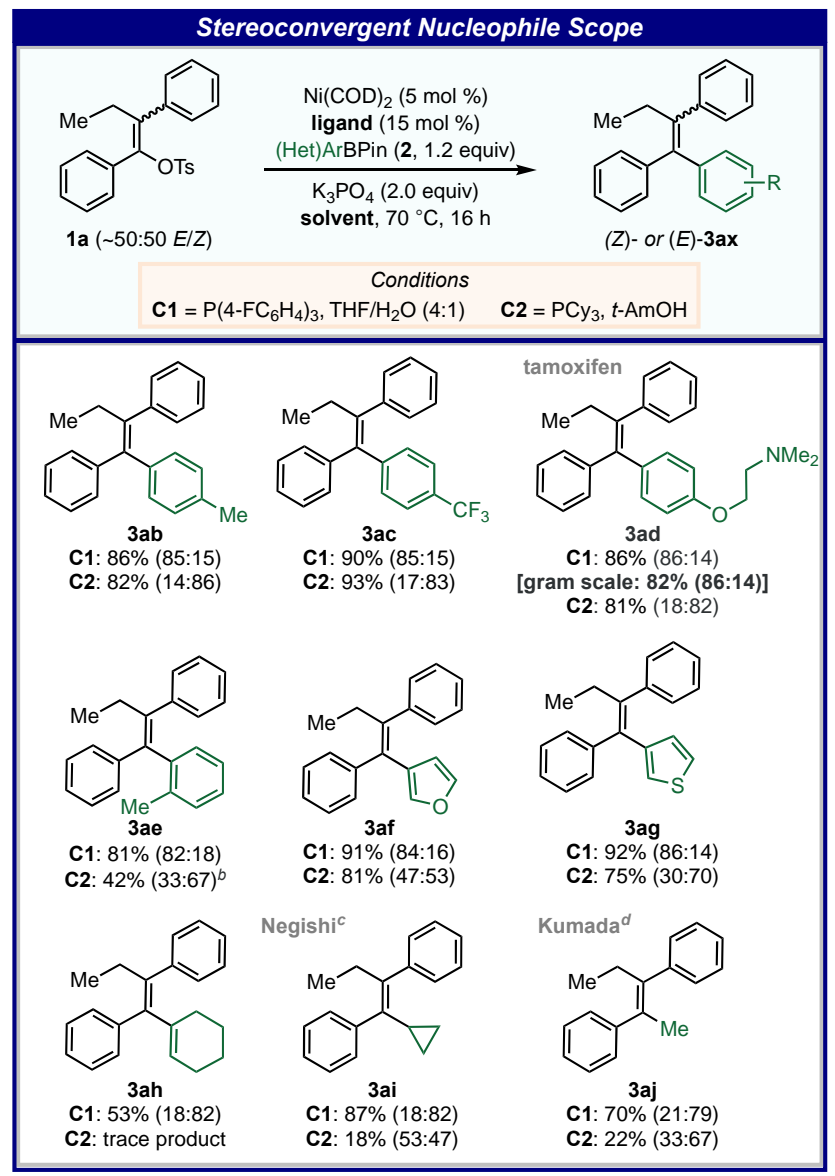

${ }^{a}$ Combined isolated yields; $(Z / E)$-diastereomeric ratio shown in parentheses. Reaction conditions C1: $(E / Z)-\mathbf{1 a}(0.25 \mathrm{mmol}$ each, 1.0 equiv), nucleophile 2 (1.2 equiv), $\mathrm{Ni}(\mathrm{COD})_{2}(5.0 \mathrm{~mol} \%), \mathbf{L 1}(15 \mathrm{~mol} \%), \mathrm{K}_{3} \mathrm{PO}_{4}$ (2.0 equiv), $70{ }^{\circ} \mathrm{C}, \mathrm{THF} / \mathrm{H}_{2} \mathrm{O}(4: 1,0.33 \mathrm{M}), 16$ h. Conditions C2: $(E / Z)-1 \mathbf{a}$ (0.25 mmol each, 1.0 equiv), nucleophile 2 (1.2 equiv), $\mathrm{Ni}(\mathrm{COD})_{2}$ (5.0 mol\%), L2 (15 mol \%), $70{ }^{\circ} \mathrm{C}, t-\mathrm{AmOH}(0.33 \mathrm{M}), 16$ h. ${ }^{b} \mathrm{Ni}(\mathrm{COD})_{2}$ $(10 \mathrm{~mol} \%), \mathbf{L 2}(30 \mathrm{~mol} \%), t-\mathrm{AmOH}(0.50 \mathrm{M}), 90^{\circ} \mathrm{C} .{ }^{c}(E / Z)-1 \mathrm{a}(0.25$ mmol each, 1.0 equiv), cyclopropylzinc bromide ( $2 \mathbf{i}, 2.0$ equiv), $\mathrm{Ni}(\mathrm{COD})_{2}$ $(10 \mathrm{~mol} \%)$, L1 or $\mathbf{L 2}(30 \mathrm{~mol} \%), 70{ }^{\circ} \mathrm{C}$, THF $(0.20 \mathrm{M}), 16$ h. ${ }^{d}(E / Z)-\mathbf{1 a}$ $\left(0.25 \mathrm{mmol}\right.$ each, 1.0 equiv), $\mathrm{MeMgBr}$ ( $\mathbf{2 j}, 2.0$ equiv), $\mathrm{Ni}(\mathrm{COD})_{2}$ (10 mol \%), L1 or L2 (30 mol \%), $70{ }^{\circ} \mathrm{C}$, THF (0.38 M), $16 \mathrm{~h}$.

Heterocycles, such as furan (leading to product 3af) and thiophene (product 3ag) were tolerated with yields up to 91 and $92 \%$, respectively. Interestingly, a pronounced selectivity drop with the furanyl pinacol boronate was only observed using conditions C2 (3af, 53:47 E/Z compared to 84:16 Z/E with C1).
This discrepancy in sensitivity to substrate once again highlights the potential mechanistic differences between the (Z)and $(E)$-selective protocols (vide infra). Notably, the stereoconvergent methodology was not restricted to Suzuki-Miyaura couplings but was also successfully demonstrated under Ni-catalyzed Kumada- and Negishi cross-coupling conditions. Accordingly, a reaction with cyclopropylzinc bromide $(\mathbf{2 i})$ as the nucleophilic coupling partner generated the desired product 3ai with conservation of the ring system and high selectivity (82:18 dr) for the $(E)$-isomer as well as $87 \%$ yield. Under the Kumada cross-coupling regime, the methylated product 3aj was afforded with a high level of stereoconvergence $(79: 21 \mathrm{E} / \mathrm{Z})$ and a yield of $70 \%$ using $\operatorname{MeMgBr}(\mathbf{2} \mathbf{j})$ with $\mathbf{L 1}$. The reaction with L2 showed promising levels of convergence $(67: 33 \mathrm{E} / \mathrm{Z})$ as well, but was lower yielding and did not produce the desired opposite diastereomer.

Scheme 3. Stereodivergent Ni-catalyzed Suzuki-Miyaura coupling of enol tosylates 1 with boronate $2 a^{a}{ }^{a}$

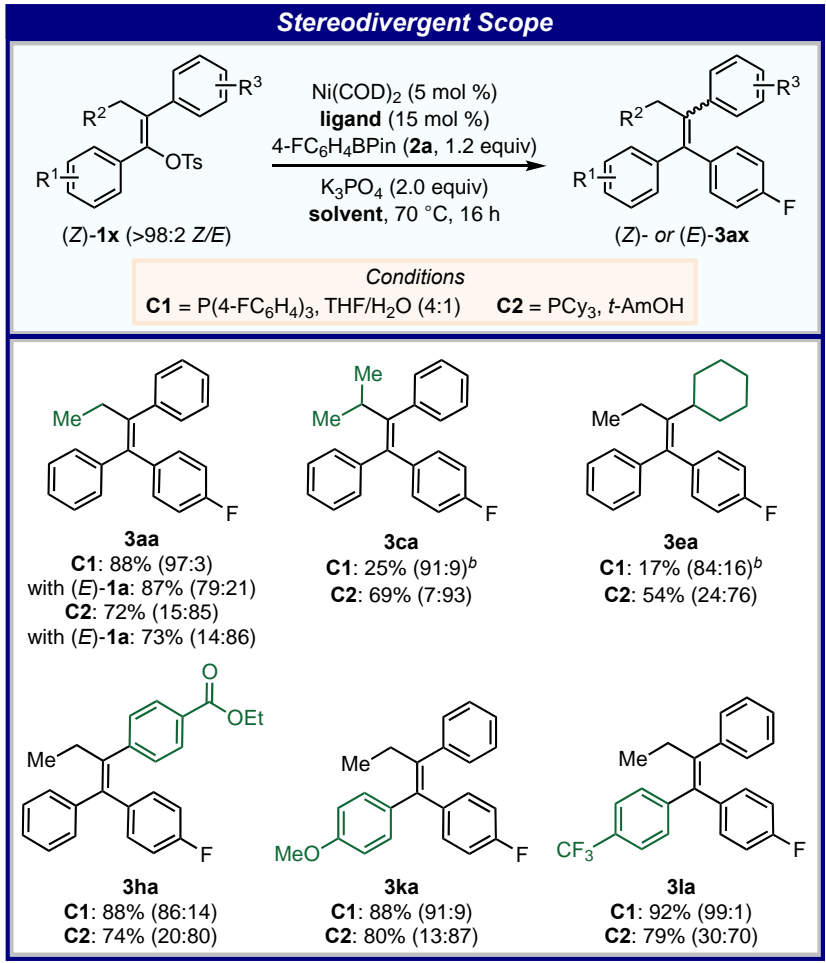

${ }^{a}$ Combined isolated yields; $(Z / E)$-diastereoselectivities shown in parentheses. Reaction conditions C1: $(Z)-\mathbf{1}(0.50 \mathrm{mmol}, 1.0$ equiv), $2 \mathrm{a}$ (1.2 equiv), $\mathrm{Ni}(\mathrm{COD})_{2}(5.0 \mathrm{~mol} \%), \mathrm{P}\left(4-\mathrm{FC}_{6} \mathrm{H}_{4}\right)_{3}(15 \mathrm{~mol} \%), \mathrm{K}_{3} \mathrm{PO}_{4}$ (2.0 equiv), $70{ }^{\circ} \mathrm{C}$, $\mathrm{THF} / \mathrm{H}_{2} \mathrm{O}(4: 1,0.33 \mathrm{M}), 16 \mathrm{~h}$. Conditions C2: $(Z)-\mathbf{1}(0.50 \mathrm{mmol}, 1.0$ equiv $)$, 2a (1.2 equiv), $\mathrm{Ni}(\mathrm{COD})_{2}(5.0 \mathrm{~mol} \%), \mathrm{PCy}_{3}(15 \mathrm{~mol} \%), 70{ }^{\circ} \mathrm{C}, t-\mathrm{AmOH}$ $(0.33 \mathrm{M}), 16$ h. ${ }^{b}$ Using $\mathrm{K}_{3} \mathrm{PO}_{4}$ (1.0 equiv), 2a (3.0 equiv), $\mathrm{Ni}(\mathrm{COD})_{2}$ (10 mol \%), L1 (30 mol \%).

We also probed the synthetic versatility of a diastereodivergent approach, which would generate tetrasubstituted alkene products $(Z)-\mathbf{3}$ or $(E)-\mathbf{3}$ selectively from diastereomerically enriched enol tosylates 1 (Scheme 3 ). Thus, several stereochemically defined $(Z)$-enol tosylates $(Z)$-1 were evaluated using a divergent protocol with the same $(Z)$ - or $(E)$-selective reaction conditions C1 or C2, respectively, as employed for the diastereoconvergent approach. Generally, both product diastereomers were obtained in high diastereomeric ratios of up to 99:1 Z/E and 93:7 $E / Z$ and typically good isolated yields of up to $92 \%$. It is notable that some of the selectivities were higher than under convergent conditions, such as for product (Z)-3aa (97:3 versus 86:14 Z/E, 
$c f$. Scheme 1). In particular, the drop in (Z)-selectivity by variation in the northwestern quadrant (3aa vs 3ca) was not observed under the divergent conditions ( $c f$. Scheme 1). Instead, the isopropyl-substituted product 3ca was isolated with a selectivity of 91:9 Z/E, albeit in moderate yield of $25 \%$. The observation that the configuration of the enol tosylate starting material could have a profound effect on selectivity of the tetrasubstituted alkene product was further investigated by probing the corresponding isomeric tosylates $(E)$-1a under both conditions $\mathbf{C 1}$ and C2. With $(E)$-1a as the starting material, a lower ratio of 79:21 $Z / E$ for 3aa was observed under the $(Z)$-selective conditions C1, whereas almost the same selectivity of $86: 14 \mathrm{E} / \mathrm{Z}$ 3aa was obtained under $(E)$-selective conditions $\mathbf{C 2}$. The observation of the same product selectivity irrespective of the starting material geometry may indicate that a Curtin-Hammett scenario is likely operative under the $(E)$-selective reaction regime. In contrast, the product selectivity in the reaction under conditions C1 is more dependent on the enol tosylate geometry, indicating a different mechanistic manifold could be effective under these conditions (vide infra, Table 1).

Mechanistic Studies. For the Curtin-Hammett principle to be applicable, the rate of isomerization should be faster than the subsequent stereodetermining step. In such a scenario, the diastereomeric composition of the starting material should have no effect on the observed selectivity of the product. As previously indicated (Scheme 3), such behavior was observed under conditions C2, but not for $\mathbf{C 1}$. To examine this discrepancy in more detail, both starting material diastereomers $(E / Z)-1 \mathbf{a}$, and a 50:50 mixture thereof was subjected to both optimized conditions and the diastereoselectivity for the formation of product 3aa was determined (Table 1). Notably, the product selectivity was significantly affected by the geometry of the starting material under conditions $\mathbf{C 1}$. Thus, a pronounced drop in the selectivity of 3aa from 99:1 Z/E starting with (Z)-1a to only 79:21 $Z / E$ with $(E)$-1a was observed (entries $1-3)$. A potential mechanistic rationale could be that the isomerization barrier is closer in energy to the subsequent stereodetermining step (approaching a "kinetic quench" scenario) for this set of conditions. ${ }^{75-77}$ In other words, $(Z)$-selectivity is favored in the stereodetermining step (due to the choice of ligand) but the rate of isomerization is too slow resulting in significant formation of $(E)$-3aa. In stark contrast, the same selectivity was observed under conditions $\mathbf{C 2}$ regardless of the $Z / E$-ratio of the starting material (entries 4-6). This behavior is consistent with typical Curtin-Hammett behavior, which is presumably caused by a lower energy barrier of the isomerization than the stereodetermining step.

Table 1. Effect of starting material 1a geometry on the selectivity of product 3aa. ${ }^{a}$

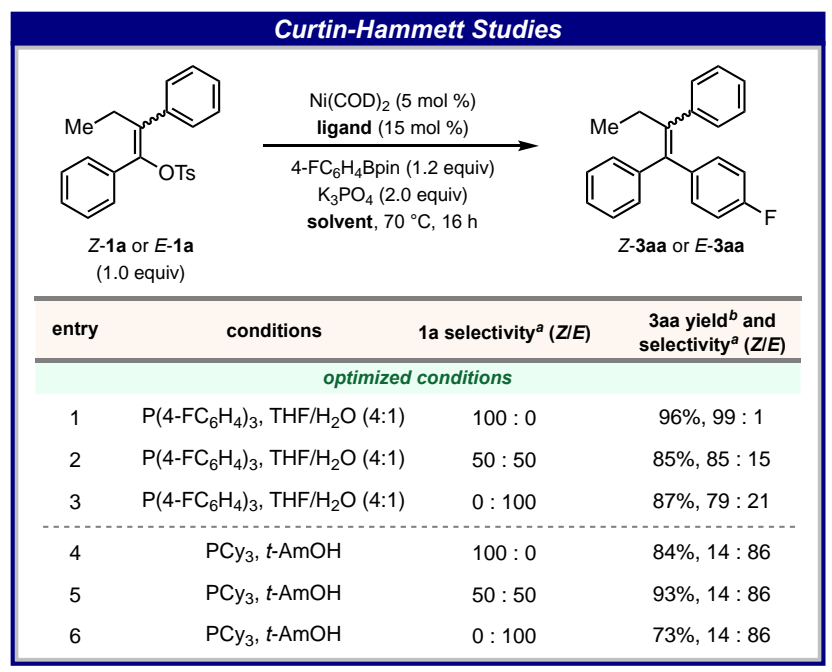

a $(Z / E)$-diastereoselectivities and yields determined by ${ }^{19} \mathrm{~F}-\mathrm{NMR}(1,4-$ difluorobenzene as the internal standard). Reaction conditions: $(Z)-,(E)$ - or 50:50 (E/Z)-1a $\left(0.10 \mathrm{mmol}, 1.0\right.$ equiv), 2a (1.2 equiv), $\mathrm{Ni}(\mathrm{COD})_{2}$ $(5.0 \mathrm{~mol} \%), \quad \mathrm{P}\left(4-\mathrm{FC}_{6} \mathrm{H}_{4}\right)_{3} \quad(15 \mathrm{~mol} \%) \quad$ or $\quad \mathrm{PCy}_{3} \quad(15 \mathrm{~mol} \%), \mathrm{K}_{3} \mathrm{PO}_{4}$ (2.0 equiv), $70{ }^{\circ} \mathrm{C}, \mathrm{THF} / \mathrm{H}_{2} \mathrm{O}(4: 1,0.33 \mathrm{M})$ or $t-\mathrm{AmOH}(0.33 \mathrm{M}), 16 \mathrm{~h}$.

To rationalize the observed behavior and selectivity of this transformation, a combination of mechanistic experiments and density functional theory (DFT) calculations was employed. Recently, there have been several investigations into Ni-catalyzed Suzuki-Miyaura cross-coupling reactions, presumably due its growing popularity as a powerful alternative to Pd-catalyzed reactions. ${ }^{54-55,78}$ However, nickel catalysis can access various different reaction mechanisms based on the catalytic system in question. Typically, $\mathrm{Ni}(0) / \mathrm{Ni}(\mathrm{II})$ catalytic cycles are proposed when phosphine ligands are employed, while $\mathrm{Ni}(\mathrm{I}) / \mathrm{Ni}(\mathrm{III})$ cycles are proposed for reactions with $N$-heterocyclic carbene and pincer-type ligands. ${ }^{78}$ The involvement of single electron transfer (SET) processes was experimentally examined by adding catalytic amounts of 2,6-di-tert-butyl-4methylphenol (BHT) as a radical inhibitor to both the $(Z)$ - and $(E)$-selective diastereodivergent conditions. In each case, the reactions were unaffected by the presence of the inhibitor (see SI for details). This observation is also supported by our DFT calculations, which suggest that $\mathrm{Ni}(0) / \mathrm{Ni}$ (II) complexes are energetically favored in participating in oxidative addition, transmetalation, and reductive elimination as compared to their open-shell $\mathrm{Ni}(\mathrm{I}) / \mathrm{Ni}(\mathrm{III})$ counterparts (see SI for details). Hence, only the closed-shell $\mathrm{Ni}(0) / \mathrm{Ni}(\mathrm{II})$ mechanisms of oxidative addition, transmetalation, and reductive elimination were investigated further with ligands $\mathbf{L 1}$ and $\mathbf{L 2}$.

Our initial mechanistic proposal was that a facile oxidative addition of the enol tosylate $\mathbf{1}$ to the Ni-complex is followed by an isomerization event, stereodetermining transmetalation, and reductive elimination (Figure 5A). However, as the exact order of the described elementary steps was unclear, detailed computational studies were performed. Geometry optimizations were conducted using the B3LYP-D3BJ functional, and energies were refined with M06L using a larger basis set and THF as an implicit solvent. Oxidative addition calculations were modeled after extensive work reported by Neufeldt and co-workers. ${ }^{79-80}$ The oxidative addition step was calculated to proceed through different transition state structures depending on the ligand on the metal (Figure 5B). A concerted five-centered pathway was favored with $\mathbf{L 1}\left(\Delta G^{\ddagger}=12.1\right.$ and $3.5 \mathrm{kcal} / \mathrm{mol}$ for the $(Z)$ - and 
(E)-alkene complex, respectively), while a $\mathrm{S}_{N} 2$-type pathway was favored with $\mathbf{L 2}\left(\Delta G^{\ddagger}=9.3\right.$ and $3.0 \mathrm{kcal} / \mathrm{mol}$ for the $(Z)$ and $(E)$-alkene complex, respectively) as the ligand. In contrast, reductive elimination was found to proceed through the same concerted three-centered transition state with both ligands (L1: (Z)-complex $\Delta G^{\ddagger}=13.7 \mathrm{kcal} / \mathrm{mol},(E)$-complex $\Delta G^{\ddagger}=7.1$ $\mathrm{kcal} / \mathrm{mol}$. L2: $(Z)$-complex $\Delta G^{\ddagger}=11.2 \mathrm{kcal} / \mathrm{mol},(E)$-complex
$\left.\Delta G^{*}=9.1 \mathrm{kcal} / \mathrm{mol}\right)$. The calculated energy barriers for these steps are readily surmountable under the reaction conditions and thus should not have an influence on the observed selectivity.

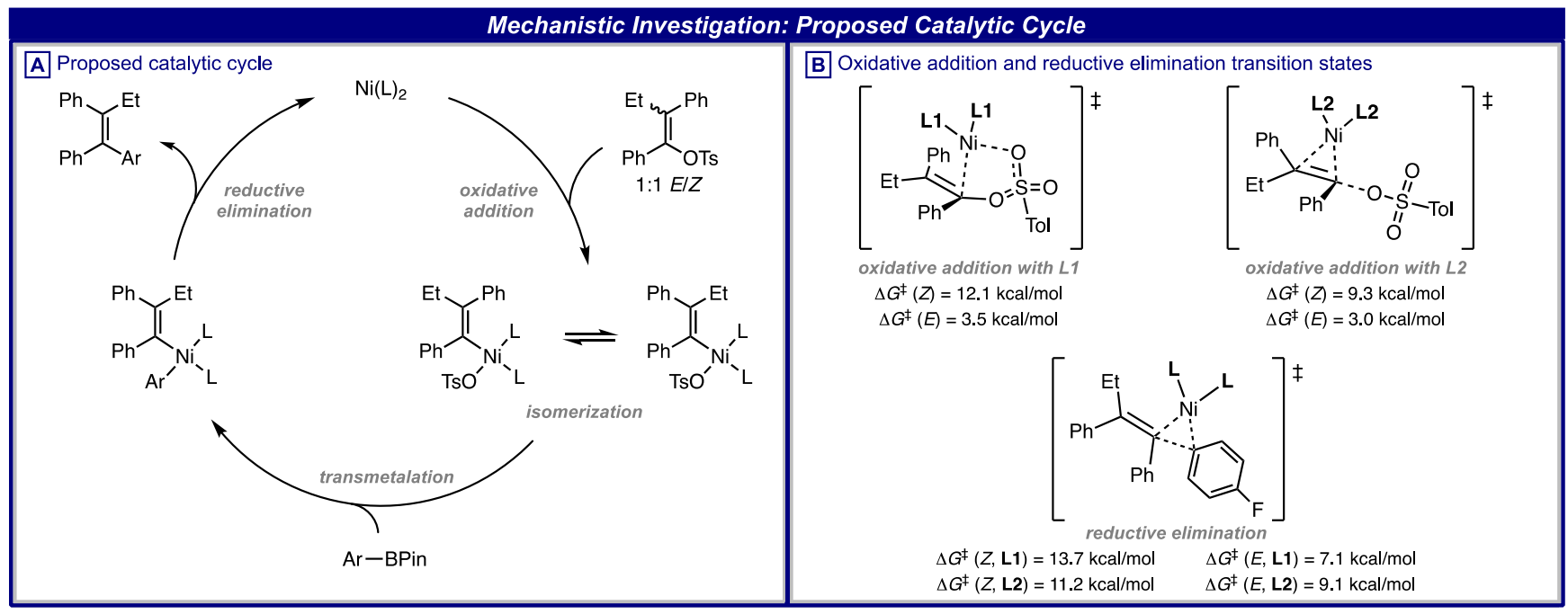

Figure 5. (A) Proposed catalytic cycle. (B) Calculated transition states and energy barriers for oxidative addition and reductive elimination with $\mathrm{P}\left(4-\mathrm{FC}_{6} \mathrm{H}_{4}\right)_{3}(\mathbf{L} \mathbf{1})$ and $\mathrm{PCy}_{3}(\mathbf{L} 2)$ as the ligands.

We then turned our attention towards elucidating a potential isomerization event and the role of transmetalation in the stereodetermining step. The precise nature of these processes was much more ambiguous. For the present reaction, the mechanistic rationale of the isomerization event was of particular interest. For Pd-catalyzed carbometalation reactions, previous reports have postulated that the isomerization of the vinyl-Pd complex occurs via zwitterionic Pd-carbenoid intermediates, which form after the carbometalation step. ${ }^{81-83}$ Alternatively, Crabtree and co-workers have proposed that the key isomerization step proceeds via formation of an $\eta^{2}$-vinyl complex for $\mathrm{Pd}$ catalyzed hydrosilylation of alkynes. ${ }^{84-85}$ Nevertheless, a deeper mechanistic understanding of this widely occurring isomerization event in cross-coupling reactions has remained elusive, especially for Ni-catalyzed reactions.

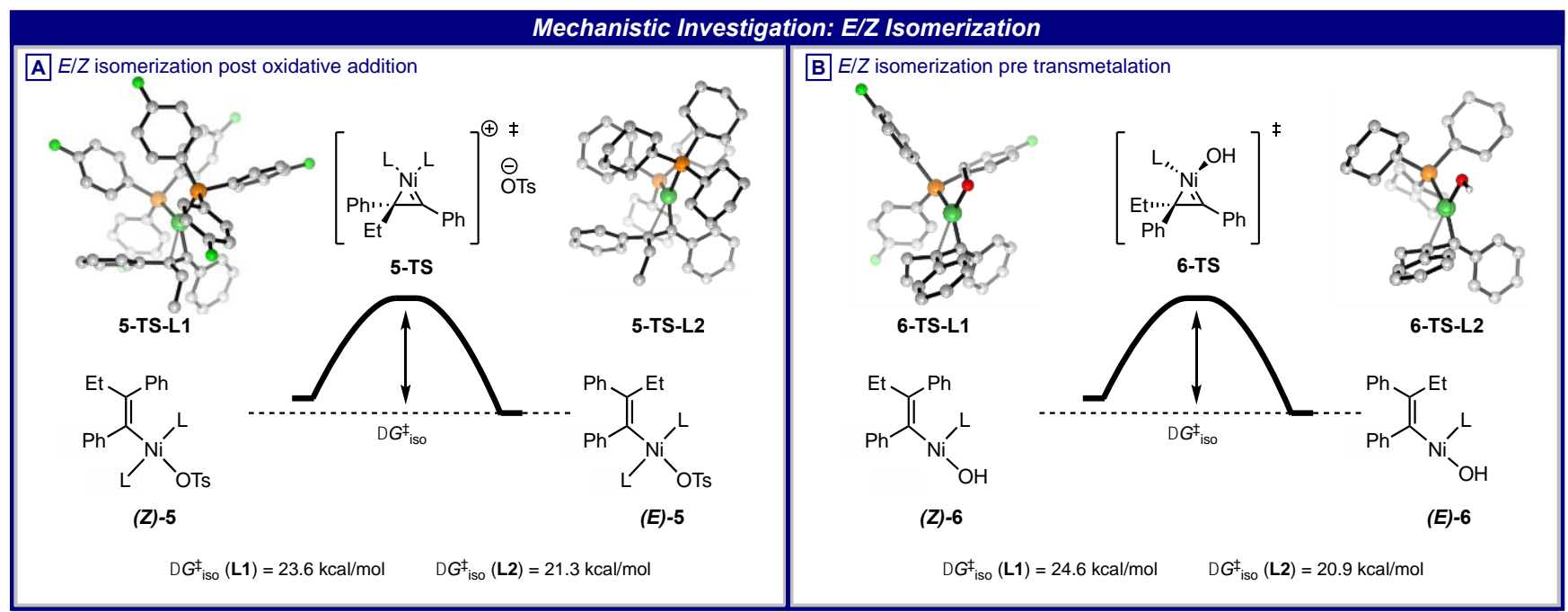

Figure 6. Calculated transition states and energy barriers for the isomerization event after oxidative addition (A) and prior to transmetalation (B) with $\mathrm{P}\left(4-\mathrm{FC}_{6} \mathrm{H}_{4}\right)_{3}(\mathbf{L 1})$ and $\mathrm{PCy}_{3}(\mathbf{L 2})$ as the ligands.

Hence, the aforementioned mechanisms of (E/Z)-alkene complex isomerization were probed at various points along the re- action coordinate (see SI for details). While most of the postulated mechanisms show rotational barriers in excess of 30-40 $\mathrm{kcal} / \mathrm{mol}$, we noted that energetically accessible isomerizations 
(20-25 kcal/mol) could be achieved through an $\eta^{2}$-vinyl complex at various points after oxidative addition and before transmetalation (Figure 6). The proposed $\eta^{2}$-vinyl complex can be formed after oxidative addition (Figure 6A) by dissociation of the tosylate, which allows the alkene to isomerize via an $\eta^{2}$ vinyl cationic transition state 5-TS with two phosphine ligands coordinated. As an alternative, the isomerization was calculated to be equally facile prior to transmetalation via the hydroxocomplex 6 (Figure 6B). For both complexes 5 and 6, the isomerization barriers were favored by $2-3 \mathrm{kcal} / \mathrm{mol}$ with $\mathbf{L} 2$ as the ligand.

Scheme 4. Mechanistic investigation of the isomerization: (A) stoichiometric oxidative addition and (B) reaction of oxidative addition complex $1 \mathrm{a}^{\prime}-\mathrm{L} 1$ with boronate $2 \mathrm{a}$ and base.

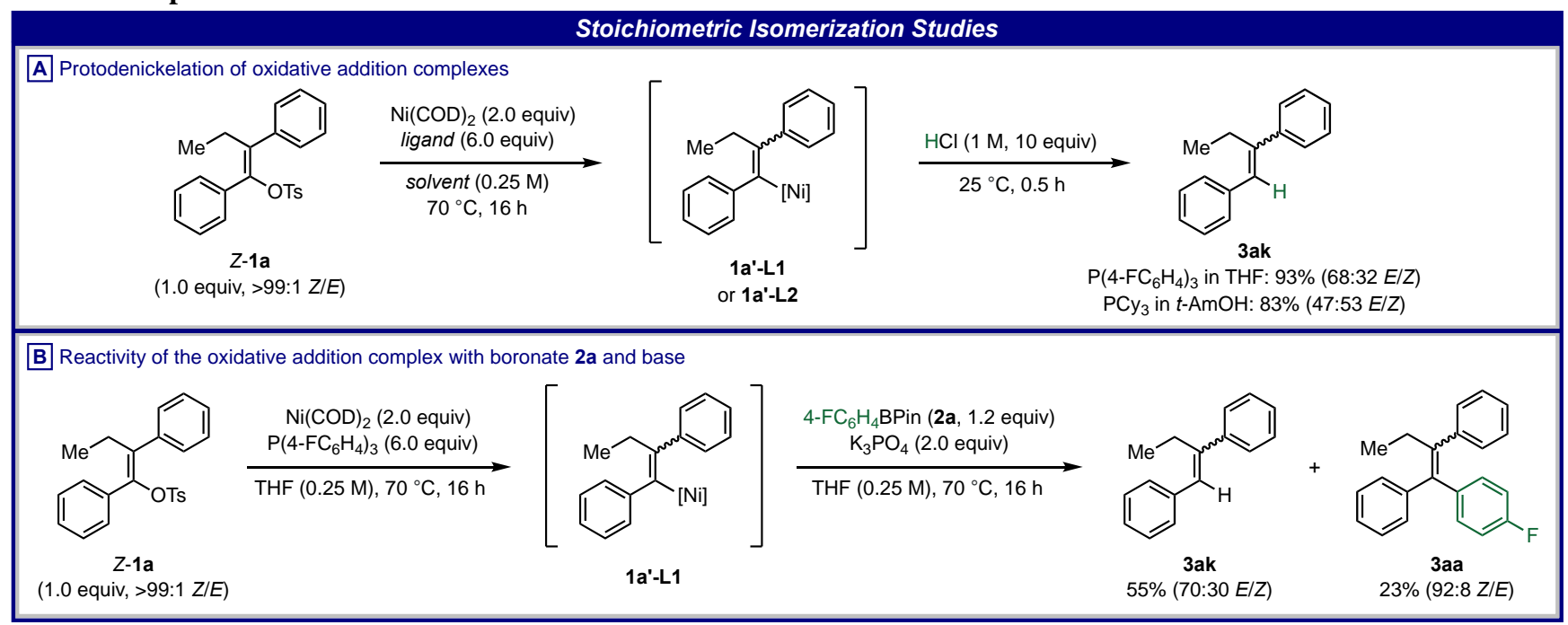

${ }^{a}$ Yields and diastereoselectivities were determined by means of HPLC-analysis and ${ }^{1} \mathrm{H}-\mathrm{NMR}$.

To experimentally investigate the hypothesis that isomerization occurs prior to transmetalation, diastereomerically pure $(Z)-\mathbf{1 a}$ was subjected to the reaction conditions with stoichiometric amounts of $\mathrm{Ni}(\mathrm{COD})_{2}$ and ligands $\mathbf{L} \mathbf{1}$ and $\mathbf{L} 2$ to access the oxidative addition complexes 1a'-L1 or 1a'-L2 (Scheme 4A). The reaction was then quenched with $1 \mathrm{M} \mathrm{HCl}$ and analyzed by ${ }^{1} \mathrm{H}-$ NMR spectroscopy. With $\mathbf{L 1}$ as the ligand in THF, the protodenickelated trisubstituted alkene 3ak was produced with 68:32 $E / Z$ selectivity and $93 \%$ yield. Using $\mathbf{L 2}$ as the ligand in $t$ $\mathrm{AmOH}$, 3ak was obtained as a diastereomeric mixture of 47:53 $E / Z$ and $83 \%$ yield. Hence, these results illustrate that the postulated isomerization step indeed precedes the transmetalation (cf. Figure 5A). To elucidate the potential role of transmetalation as the stereodetermining step, we subjected the oxidative addition complex 1a'-L1 formed in situ to the transmetalation conditions by addition of pinacol boronate $\mathbf{2 a}$ and $\mathrm{K}_{3} \mathrm{PO}_{4}$ (Scheme 4B). Thus, product 3aa was afforded in $23 \%$ yield and notably with a diastereoselectivity as high as 92:8 Z/E, which is comparable to the selectivity observed in the catalytic reaction (97:3 Z/E, Scheme 3). Of note, the major product in this reaction was the trisubstituted alkene 3ak with $55 \%$ yield and a selectivity of $70: 30 \mathrm{E} / \mathrm{Z}$, which is similar to the previously obtained selectivity of 68:32 E/Z after acidic quench (Scheme 4A). The analogous transmetalation reaction with 1a'-L2 in $t$ AmOH did not yield measurable amounts of product 3aa (see SI for details). This could potentially be rationalized in terms of a less stable oxidative addition complex $\mathbf{1} \mathbf{a}^{\prime}-\mathbf{L} \mathbf{2}$ and potential com- or disproportionation degradation pathways. ${ }^{86}$ In addition to the stoichiometric isomerization experiments, product isomerization under both optimized reaction conditions was excluded, as no significant isomerization nor decomposition was detected upon subjecting $(Z)$-3aa to the $(E)$-selective conditions C2 nor $(E)$-3aa to the $(Z)$-selective conditions C1 (see SI for details). 


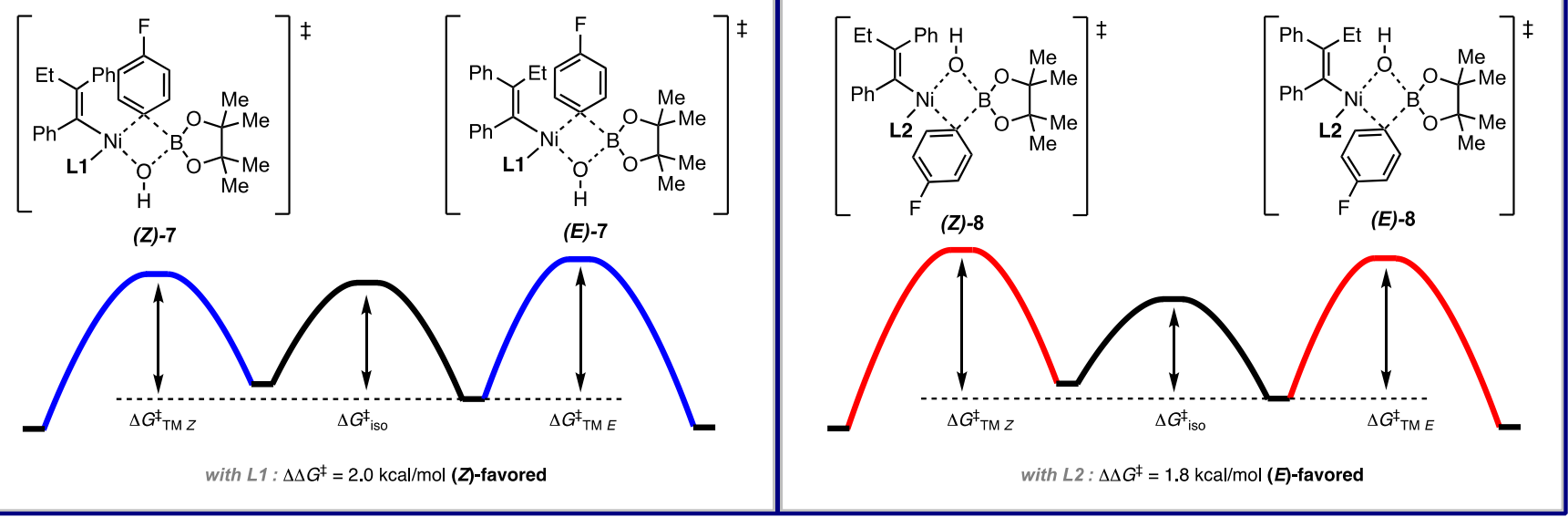

Figure 7. (A) Calculated relative free energies $\left(\Delta \Delta G^{\ddagger}\right)$ of the diastereomeric transmetalation transition states $(Z)$ - and $(E)$-7 with $\mathrm{P}\left(4-\mathrm{FC} \mathrm{H}_{6} \mathrm{H}_{4}\right)_{3}$ $(\mathbf{L 1})$ and $(\mathrm{B})(Z)$ - and $(E)-8$ with $\mathrm{PCy}_{3}(\mathbf{L 2})$ as the ligand in THF.

With the accumulated data in hand, transmetalation was extensively investigated using DFT to rationalize the experimentally observed diastereoselectivity. The formation of Ni-hydroxo dimer species under similar Suzuki-Miyaura cross-coupling conditions to those employed in our study was recently reported by Grimaud and coworkers, among others. ${ }^{87-90}$ According to their detailed study, dimer formation post oxidative addition was shown to depend on the reaction conditions. Hence, it is likely that catalytically active Ni-hydroxo dimers are formed, especially under conditions $\mathbf{C 1}$ in $\mathrm{THF} / \mathrm{H}_{2} \mathrm{O}$. These structures are also supported by DFT calculations, where they are calculated to be the lowest ground state structures preceding transmetalation (see the SI). We modeled our transmetalation calculations for the $(Z)$-selective conditions using dimer structures as starting points and assumed boronic acid induced dissociation and association of pinacol boronate to form transient transmetalation complexes analogous to transmetalation in Pd-catalyzed Suzuki-Miyaura cross-coupling reported by Denmark and coworkers. ${ }^{91}$ After conducting a comprehensive search of transition state structures, we arrived at transition states $\mathbf{7}$ and $\mathbf{8}$ (Figure 7). With $\mathbf{L 1}$ as the ligand (Figure 7A), it was found that a cis-configuration of the alkene and aryl ligands on the Ni-center is the energetically preferred geometry. The energy gap between the two transition state structures $(Z)$ - and $(E)-7$ is $\Delta \Delta G^{\ddagger}$ $=2.0 \mathrm{kcal} / \mathrm{mol}$ and thus in favor of $(Z)$-alkene complex (Figure 7A). This agrees with the experimentally observed ( $Z$ )-selectivity using $\mathbf{L} \mathbf{1}$ in $\mathrm{THF} / \mathrm{H}_{2} \mathrm{O}$ (conditions C1). However, with L2 as the ligand (Figure 7B), the analogous transmetalation transition structures $(Z)$ - and $(E)-8$ place the alkene and aryl fragments in a trans-configuration. The energy difference between the diastereomeric transition states $(Z)$ - and $(E)-\mathbf{8}$ in this case is $\Delta \Delta G^{*}=1.8 \mathrm{kcal} / \mathrm{mol}$, in favor of $(E)-\mathbf{8}$, which is again in good agreement with the selectivity observed when employing conditions C2. However, more detailed insight into the transmetalation step and its corresponding ground states is obfuscated by its complicated nature. For example, it is unclear whether the boronate ester undergoes partial or full hydrolysis prior to transmetalation under the reaction conditions. ${ }^{92}$ Computational results support both boronic acid and pinacol boronate giving rise to a similar selectivity, which is in alignment with experimental results wherein comparable diastereoselectivities of product 3aa were observed upon replacing pinacol boronate $\mathbf{2 a}$ with its boronic acid analog $\mathbf{2} \mathbf{a}^{\prime}$ under both conditions $\mathbf{C 1}$ and
C2 (see SI, Table S-2). Although the precise details of the transmetalation step and the corresponding ground states remain unclear, the combination of experimental and computational observations described above support the mechanistic rationale that a facile oxidative addition precedes an isomerization equilibrium, followed by a selectivity-determining transmetalation.

\section{Conclusion}

In summary, we have developed nickel-catalyzed cross-coupling reactions that enable a diastereodivergent and diastereoconvergent synthesis of tetrasubstituted alkenes from readily available enol tosylates. Notably, a data-rich high throughput optimization was guided by the kraken organophosphorus(III) descriptor library to identify a set of stereocomplementary monophosphine ligands. The methodology was successfully demonstrated on various tetrasubstituted alkene scaffolds and showed consistently high levels of yields and selectivities. Detailed experimental and computational studies provided insight into the complex catalytic system of this transformation and shed light on the key steps, isomerization and transmetalation, that influence the ligand dependent outcome of this reaction. Moreover, the applicability of this protocol was extended to Negishi and Kumada cross-coupling reactions. We plan to utilize the improved mechanistic understanding of this transformation to explore and develop similar isomerization processes. Finally, the application of the kraken organophosphorus(III) descriptor library in combination with high throughput experimentation is an emerging tool that we plan to continue to expand and exploit in the systematic and more streamlined optimization of other complex catalytic reactions. 


\section{ASSOCIATED CONTENT}

The Supporting Information is available free of charge at http://pubs.acs.org."

Experimental procedures, characterization and spectral data for all new compounds.

\section{AUTHOR INFORMATION}

\section{Corresponding Authors}

\section{* Daniel Zell}

Department of Small Molecule Process Chemistry, Genentech, Inc., 1 DNA Way, South San Francisco, California 94080, United States

\section{* Matthew S. Sigman}

Department of Chemistry, University of Utah, Salt Lake City, Utah 84112, United States

\section{Authors}

\section{Cian Kingston}

Department of Chemistry, University of Utah, Salt Lake City, Utah 84112, United States

\section{Janis Jermaks}

Department of Small Molecule Process Chemistry, Genentech, Inc., 1 DNA Way, South San Francisco, California 94080, United States

\section{Sleight R. Smith}

Department of Chemistry, University of Utah, Salt Lake City, Utah 84112, United States

\section{Natalie Seeger}

Department of Chemistry, University of Utah, Salt Lake City, Utah 84112, United States

\section{Jana Wassmer}

Department of Small Molecule Process Chemistry, Genentech, Inc., 1 DNA Way, South San Francisco, California 94080, United States

\section{Lauren E. Sirois}

Department of Small Molecule Process Chemistry, Genentech, Inc., 1 DNA Way, South San Francisco, California 94080, United States

\section{Haiming Zhang}

Department of Small Molecule Process Chemistry, Genentech, Inc., 1 DNA Way, South San Francisco, California 94080, United States

\section{Chong Han}

Department of Small Molecule Process Chemistry, Genentech, Inc., 1 DNA Way, South San Francisco, California 94080, United States

\section{Francis Gosselin}

Department of Small Molecule Process Chemistry, Genentech, Inc., 1 DNA Way, South San Francisco, California 94080, United States

\section{Author Contributions}

These authors contributed equally.

\section{Funding Sources}

M.S.S. acknowledges financial support from NSF under the CCI Center for Computer Assisted Synthesis (CHE-1925607).

\section{ACKNOWLEDGMENT}

We thank Dr. Christopher M. Crittenden for HRMS analysis and Dr. Antonio DiPasquale for X-Ray analysis. We would furthermore like to thank Colin Masui and Minhthi Bui for their support with the high throughput experiments.

\section{REFERENCES}

1. Jordan, V. C., Tamoxifen: catalyst for the change to targeted therapy. Eur. J. Cancer 2008, 44, 30-38.

2. Levenson, A.; Jordan, V. C., Selective oestrogen receptor modulation: molecular pharmacology for the millennium. Eur. J. Canc. 1999, 35, 1974-1985.

3. Nilsson, S.; Gustafsson, J. Å., Estrogen receptors: therapies targeted to receptor subtypes. Clin. Pharmacol. Ther. 2011, 89, 44-55.

4. McCague, R.; Leclercq, G.; Legros, N.; Goodman, J.; Blackburn, G. M.; Jarman, M.; Foster, A. B., Derivatives of tamoxifen. Dependence of antiestrogenicity on the 4-substituent. J. Med. Chem. 1989, $32,2527-2533$.

5. Savage, S.; McClory, A.; Zhang, H.; Cravillion, T.; Lim, N. K.; Masui, C.; Robinson, S. J.; Han, C.; Ochs, C.; Rege, P. D.; Gosselin, F., Synthesis of Selective Estrogen Receptor Degrader GDC-0810 via Stereocontrolled Assembly of a Tetrasubstituted All-Carbon Olefin. J. Org. Chem. 2018, 83, 11571-11576.

6. Lai, A.; Kahraman, M.; Govek, S.; Nagasawa, J.; Bonnefous, C.; Julien, J.; Douglas, K.; Sensintaffar, J.; Lu, N.; Lee, K. J.; Aparicio, A.; Kaufman, J.; Qian, J.; Shao, G.; Prudente, R.; Moon, M. J.; Joseph, J. D.; Darimont, B.; Brigham, D.; Grillot, K.; Heyman, R.; Rix, P. J.; Hager, J. H.; Smith, N. D., Identification of GDC-0810 (ARN-810), an Orally Bioavailable Selective Estrogen Receptor Degrader (SERD) that Demonstrates Robust Activity in Tamoxifen-Resistant Breast Cancer Xenografts. J. Med. Chem. 2015, 58, 4888-904.

7. Ariazi, E. A.; Ariazi, J. L.; Cordera, F.; Jordan, V. C., Estrogen receptors as therapeutic targets in breast cancer. Curr. Top. Med. Chem. 2006, 6, 181-202.

8. Riggs, B. L.; Hartmann, L. C., Selective estrogen-receptor modulators - mechanisms of action and application to clinical practice. $N$. Engl. J. Med. 2003, 348, 618-629.

9. Y Maximov, P.; M Lee, T.; Craig Jordan, V., The discovery and development of selective estrogen receptor modulators (SERMs) for clinical practice. Curr. Clin. Pharmacol. 2013, 8, 135-155.

10. Tietze, L. F.; Waldecker, B.; Ganapathy, D.; Eichhorst, C.; Lenzer, T.; Oum, K.; Reichmann, S. O.; Stalke, D., Four- and Sixfold Tandem-Domino Reactions Leading to Dimeric Tetrasubstituted Alkenes Suitable as Molecular Switches. Angew. Chem. Int. Ed. 2015, 54, $10317-$ 10321.

11. Tietze, L. F.; Düfert, M. A.; Hungerland, T.; Oum, K.; Lenzer, T., Synthesis and photochemical investigations of tetrasubstituted alkenes as molecular switches-the effect of substituents. Chem. Eur. J. 2011, 17, $8452-8461$.

12. Liu, Y.; Lv, Y.; Xi, H.; Zhang, X.; Chen, S.; Lam, J. W.; Kwok, R. T.; Mahtab, F.; Kwok, H. S.; Tao, X., Enlarged tetrasubstituted alkenes with enhanced thermal and optoelectronic properties. Chem. Comm. 2013, 49, 7216-7218.

13. Schreivogel, A.; Maurer, J.; Winter, R.; Baro, A.; Laschat, S., Synthesis and electrochemical properties of tetrasubstituted tetraphenylethenes. Eur. J. Org. Chem. 2006, 2006, 3395-3404.

14. Schultz, A.; Diele, S.; Laschat, S.; Nimtz, M., Novel columnar tetraphenylethenes via McMurry coupling. Adv. Compos. Mater. 2001, 11, 441-446.

15. Mukherjee, N.; Planer, S.; Grela, K., Formation of tetrasubstituted C-C double bonds via olefin metathesis: challenges, catalysts, and applications in natural product synthesis. Org. Chem. Front. 2018, 5, 494-516.

16. Polák, P.; Váňová, H.; Dvořák, D.; Tobrman, T., Recent progress in transition metal-catalyzed stereoselective synthesis of acyclic all-carbon tetrasubstituted alkenes. Tetrahedron Lett. 2016, 57, 3684-3693. 
17. Müller, D.; Marek, I., Copper mediated carbometalation reactions. Chem. Soc. Rev. 2016, 45, 4552-4566.

18. Flynn, A. B.; Ogilvie, W. W., Stereocontrolled synthesis of tetrasubstituted olefins. Chem. Rev. 2007, 107, 4698-4745.

19. Buttard, F.; Sharma, J.; Champagne, P. A., Recent advances in the stereoselective synthesis of acyclic all-carbon tetrasubstituted alkenes. Chem. Comm. 2021, 57, 4071-4088.

20. Lim, N. K.; Weiss, P.; Li, B. X.; McCulley, C. H.; Hare, S. R.; Bensema, B. L.; Palazzo, T. A.; Tantillo, D. J.; Zhang, H.; Gosselin, F., Synthesis of Highly Stereodefined Tetrasubstituted Acyclic All-Carbon Olefins via a Syn-Elimination Approach. Org. Lett. 2017, 19, 6212-6215.

21. Takeda, T., Modern Carbonyl Olefination: Methods and Applications, John Wiley \& Sons, 2006.

22. Maryanoff, B. E.; Reitz, A. B., The Wittig olefination reaction and modifications involving phosphoryl-stabilized carbanions. Stereochemistry, mechanism, and selected synthetic aspects. Chem. Rev. 1989, 89, 863-927.

23. Kelly, S. E., Alkene synthesis. Comp. Org. Syn. 1991, 1, 729.

24. Shimizu, M.; Nakamaki, C.; Shimono, K.; Schelper, M.; Kurahashi, T.; Hiyama, T., Stereoselective cross-coupling reaction of 1, 1diboryl-1-alkenes with electrophiles: A highly stereocontrolled approach to 1, 1, 2-triaryl-1-alkenes. J. Am. Chem. Soc. 2005, 127, 12506-12507.

25. Itami, K.; Kamei, T.; Yoshida, J.-i., Diversity-oriented synthesis of tamoxifen-type tetrasubstituted olefins. J. Am. Chem. Soc. 2003, 125, 14670-14671.

26. Stüdemann, T.; Knochel, P., New Nickel-Catalyzed Carbozincation of Alkynes: A Short Synthesis of (Z)-Tamoxifen. Angew. Chem. Int. Ed. 1997, 36, 93-95.

27. Miller, R. B.; Al-Hassan, M. I., Stereospecific synthesis of (Z)tamoxifen via carbometallation of alkynylsilanes. J. Org. Chem. 1985, 50 , 2121-2123.

28. McKinley, N. F.; O'Shea, D. F., Carbolithiation of diphenylacetylene as a stereoselective route to (Z)-tamoxifen and related tetrasubstituted olefins. J. Org. Chem. 2006, 71, 9552-9555.

29. Gigant, N.; Quintin, F.; Bäckvall, J.-E., Preparation of Tetrasubstituted Olefins Using Mono or Double Aerobic Direct C-H Functionalization Strategies: Importance of Steric Effects. J. Org. Chem. 2015, 80, 2796-2803.

$30 . \quad$ He, Z; Wibbeling, B.; Studer, A., Oxidative Heck Coupling of Allylic Amines with 2, 2, 6, 6-Tetramethylpiperidine-N-oxyl (TEMPO) as Oxidant for the Preparation of Tetrasubstituted Alkenes. Adv. Synth. Catal. 2013, 355, 3639-3647

31. He, Z; Kirchberg, S.; Fröhlich, R.; Studer, A., Oxidative Heck arylation for the stereoselective synthesis of tetrasubstituted olefins using nitroxides as oxidants. Angew. Chem. Int. Ed. 2012, 51, 3699-3702.

32. Kim, K. H.; Lee, S.; Kim, S. H.; Lim, C. H.; Kim, J. N., Palladium-catalyzed arylation of a,b-unsaturated Weinreb amides. Tetrahedron Lett. 2012, 53, 5088-5093.

33. Lee, H. S.; Kim, K. H.; Kim, S. H.; Kim, J. N., PalladiumCatalyzed, Chelation-Assisted Stereo- and Regioselective Synthesis of Tetrasubstituted Olefins by Oxidative Heck Arylation. Adv. Synth. Catal. 2012, 354, 2419-2426.

34. Saini, V.; O'Dair, M.; Sigman, M. S., Synthesis of highly functionalized tri-and tetrasubstituted alkenes via Pd-catalyzed 1, 2 hydrovinylation of terminal 1, 3-dienes. J. Am. Chem. Soc. 2015, 137, 608611 .

35. Ashida, Y.; Nakata, K.; Yoshitake, D.; Sato, Y.; Miyazaki, Y.; Tanabe, Y., (E)-,(Z)-Stereodefined $\alpha$-Chloro- $\beta$-tosyloxy- $\alpha, \beta$ unsaturated Esters: Sequential Cross-couplings for (E)-,(Z)-Stereo complementary Synthesis of Fully-substituted $\alpha, \beta$-Unsaturated Esters. Asian J. Org. Chem. 2020

36. Christensen, M. Y., L.; Adedeji, F.; Haese, F; Roch, L.; Gensch, T.; Dos Passos Gomes, G.; Zepel, T.; Sigman, M.; Aspuru-Guzik, A.; Hein, J., Commun. Chem. 2020, 4, 112.

37. Trost, B. M.; Tracy, J. S., Vanadium-Catalyzed Synthesis of Geometrically Defined Acyclic Tri- and Tetrasubstituted Olefins from Propargyl Alcohols. ACS Catal. 2019, 9, 1584-1594.

38. Li, J.; Knochel, P., Cobalt-Catalyzed Cross-Couplings between Alkenyl Acetates and Aryl or Alkenyl Zinc Pivalates. Angew. Chem. Int. Ed. 2018, 57, 11436-11440.

39. Tanabe, Y.; Sato, Y.; Ashida, Y.; Yoshitake, D.; Hoshino, M.; Takemoto, T., Stereoretentive Suzuki-Miyaura and Kumada-TamaoCorriu Cross-Couplings for Preparing (E)- and (Z)-Stereodefined, Fully Substituted $\alpha, \beta$-Unsaturated Esters: Application for a Pharmacophore Synthesis. Synthesis 2018, 50, 4659-4667.

40. Rivera, A. C. P.; Still, R.; Frantz, D. E., Iron-Catalyzed Stereoselective Cross-Coupling Reactions of Stereodefined Enol
Carbamates with Grignard Reagents. Angew. Chem. Int. Ed. 2016, 55, 6689-6693.

41. Christensen, M.; Nolting, A.; Shevlin, M.; Weisel, M.; Maligres, P. E.; Lee, J.; Orr, R. K.; Plummer, C. W.; Tudge, M. T.; Campeau, L. C.; Ruck, R. T., Enantioselective Synthesis of $\alpha$-Methyl- $\beta$ cyclopropyldihydrocinnamates. J. Org. Chem. 2016, 81, 824-30.

42. Molinaro, C.; Scott, J. P.; Shevlin, M.; Wise, C.; Menard, A.; Gibb, A.; Junker, E. M.; Lieberman, D., Catalytic, asymmetric, and stereodivergent synthesis of non-symmetric $\beta, \beta$-diaryl- $\alpha$-amino acids. $J$. Am. Chem. Soc. 2015, 137, 999-1006.

43. Li, B. X.; Le, D. N.; Mack, K. A.; McClory, A.; Lim, N. K.; Cravillion, T.; Savage, S.; Han, C.; Collum, D. B.; Zhang, H.; Gosselin, F., Highly Stereoselective Synthesis of Tetrasubstituted Acyclic AllCarbon Olefins via Enol Tosylation and Suzuki-Miyaura Coupling. J. Am. Chem. Soc. 2017, 139, 10777-10783.

44. Krasovskiy, A.; Lipshutz, B. H., Ligand Effects on Negishi Couplings of Alkenyl Halides. Org. Lett. 2011, 13, 3818-3821.

45. Lu, G. P.; Voigtritter, K. R.; Cai, C.; Lipshutz, B. H., Ligand effects on the stereochemical outcome of Suzuki-Miyaura couplings. $J$. Org. Chem. 2012, 77, 3700-3.

46. Krasovskiy, A.; Duplais, C.; Lipshutz, B. H., Stereoselective Negishi-like couplings between alkenyl and alkyl halides in water at room temperature. Org. Lett. 2010, 12, 4742-4744.

47. Mack, K. A.; McClory, A.; Zhang, H.; Gosselin, F.; Collum D. B., Lithium Hexamethyldisilazide-Mediated Enolization of Highly Substituted Aryl Ketones: Structural and Mechanistic Basis of the E/Z Selectivities. J. Am. Chem. Soc. 2017, 139, 12182-12189.

48. Harper, K. C.; Sigman, M. S., Using Physical Organic Parameters To Correlate Asymmetric Catalyst Performance. J. Org. Chem. 2013, 78, 2813-2818

49. $\quad$ Sigman, M. S.; Harper, K. C.; Bess, E. N.; Milo, A., The Development of Multidimensional Analysis Tools for Asymmetric Catalysis and Beyond. Acc. Chem. Res. 2016, 49, 1292-301.

50. Wu, K.; Doyle, A. G., Parameterization of phosphine ligands demons trates enhancement of nickel catalysis via remote steric effects. Nat. Chem. 2017, 9, 779-784.

51. Reid, J. P.; Sigman, M. S., Comparing quantitative prediction methods for the discovery of small-molecule chiral catalysts. Nat. Rev. Chem. 2018, 2, 290-305.

52. Santiago, C. B.; Guo, J.-Y.; Sigman, M. S., Predictive and mechanistic multivariate linear regression models for reaction development. Chem. Sci. 2018, 9, 2398-2412.

53. Nassar, Y.; Rodier, F.; Ferey, V.; Cossy, J., Cross-Coupling of Ketone Enolates with Grignard and Zinc Reagents with First-Row Transition Metal Catalysts. ACS Catal. 2021, 11, 5736-5761.

54. Tasker, S. Z.; Standley, E. A.; Jamison, T. F., Recent advances in homogeneous nickel catalysis. Nature 2014, 509, 299-309.

55. Han, F. S., Transition-metal-catalyzed Suzuki-Miyaura crosscoupling reactions: a remarkable advance from palladium to nickel catalysts. Chem. Soc. Rev. 2013, 42, 5270-98.

56. Shimasaki, T.; Konno, Y.; Tobisu, M.; Chatani, N., Nickelcatalyzed cross-coupling reaction of alkenyl methyl ethers with aryl boronic esters. Org. Lett. 2009, 11, 4890-4892.

57. Ohtsuki, A.; Sakurai, S.; Tobisu, M.; Chatani, N., Nickelcatalyzed Ring-opening Cross-coupling of Cyclic Alkenyl Ethers with Arylboronic Esters via Carbon-Oxygen Bond Cleavage. Chem. Lett. 2016, $45,1277-1279$.

58. Ho, G. M.; Sommer, H.; Marek, I., Highly E-Selective, Stereoconvergent Nickel-Catalyzed Suzuki-Miyaura Cross-Coupling of Alkenyl Ethers. Org. Lett. 2019, 21, 2913-2917.

59. Chehal, N. K.; Budzelaar, P. H. M.; Hultin, P. G., E-Z isomerization in Suzuki cross-couplings of haloenones: ligand effects and evidence for a separate catalytic cycle. Org. Biomol. Chem. 2018, 16, 11341143.

60. Dobson, C. M., Chemical space and biology. Nature 2004, 432, 824-828.

61. Crawford, J. M.; Kingston, C.; Toste, F. D.; Sigman, M. S., Acc. Chem. Res. 2021, https://doi.org/10.1021/acs.accounts.1c00285.

62. Gensch, T.; dos Passos Gomes, G.; Friederich, P.; Peters, E.; Gaudin, T.; Pollice, R.; Jorner, K.; Nigam, A.; Lindner D'Addario, M.; Sigman, M. S.; Aspuru-Guzik, A., A Comprehensive Discovery Platform for Organophosphorus Ligands for Catalysis. ChemRxiv 2021, 10.26434/chemrxiv.12996665.v1

63. Jolliffe, I. T.; Cadima, J., Principal component analysis: a review and recent developments. Philos. Trans. R. Soc. A 2016, 374, 20150202 . 
64. McInnes, L.; Healy, J.; Melville, J., UMAP: Uniform Manifold Approximation and Projection for Dimension Reduction. 2018, arXiv Preprint Feb 9, 2018, arXiv:1802.03426 [stat.ML]. https://arxiv.org/abs/1802.03426 (accessed 2021-5-1).

65. Probst, D.; Reymond, J.-L., Visualization of very large highdimensional data sets as minimum spanning trees. J. Cheminformatics 2020, $12,12$.

66. Zhang, S.-Q.; Taylor, B. L. H.; Ji, C.-L.; Gao, Y.; Harris, M. R.; Hanna, L. E.; Jarvo, E. R.; Houk, K. N.; Hong, X., Mechanism and Origins of Ligand-Controlled Stereoselectivity of Ni-Catalyzed SuzukiMiyaura Coupling with Benzylic Esters: A Computational Study. J. Am. Chem. Soc. 2017, 139, 12994-13005.

67. Zim, D.; Lando, V. R.; Dupont, J.; Monteiro, A. L., $\mathrm{NiCl}_{2}\left(\mathrm{PCy}_{3}\right)_{2}$ : A Simple and Efficient Catalyst Precursor for the Suzuki Cross-Coupling of Aryl Tosylates and Arylboronic Acids. Org. Lett. 2001 3, 3049-3051.

68. Li, Z.; Zhang, S.-L.; Fu, Y.; Guo, Q.-X.; Liu, L., Mechanism of Ni-Catalyzed Selective C-O Bond Activation in Cross-Coupling of Aryl Esters. J. Am. Chem. Soc. 2009, 131, 8815-8823.

69. Suresh, C. H.; Koga, N., Quantifying the Electronic Effect of Substituted Phosphine Ligands via Molecular Electrostatic Potential. Inorg Chem. 2002, 41, 1573-1578.

70. Poater, A.; Cosenza, B.; Correa, A.; Giudice, S.; Ragone, F.; Scarano, V.; Cavallo, L., SambVca: A Web Application for the Calculation of the Buried Volume of N-Heterocyclic Carbene Ligands. Eur. J. Inorg. Chem. 2009, 2009, 1759-1766.

71. Clavier, H.; Nolan, S. P., Percent buried volume for phosphine and $\mathrm{N}$-heterocyclic carbene ligands: steric properties in organometallic chemistry. Chem. Comm. 2010, 46, 841-861.

72. Newman-Stonebraker, S.; Smith, S.; Borowski, J.; Peters, E. Gensch, T.; Johnson, H.; Sigman, M.; Doyle, A., Linking Mechanistic Analysis of Catalytic Reactivity Cliffs to Ligand Classification. ChemRxiv 2021, 10.26434/chemrxiv.14388557.v1.

73. Ashida, Y.; Honda, A.; Sato, Y.; Nakatsuji, H.; Tanabe, Y., Divergent Synthetic Access to E- and Z-Stereodefined All-CarbonSubstituted Olefin Scaffolds: Application to Parallel Synthesis of (E)- and (Z)-Tamoxifens. ChemistryOpen 2017, 6, 73-89.

74. Heijnen, D.; van Zuijlen, M.; Tosi, F.; Feringa, B. L., An atom efficient synthesis of tamoxifen. Org. Biomol. Chem. 2019, 17, 2315-2320.

75. Eliel, E. L.; Wilen, S. H., Stereochemistry of Organic Compounds, John Wiley \& Sons, 1994.

76. Meyers, A.; Seefeld, M. A.; Lefker, B. A.; Blake, J. F., Origin of stereochemistry in simple pyrrolidinone enolate alkylations. J. Am. Chem. Soc. 1997, 119, 4565-4566.

77. Chakraborty, S.; Saha, C., The Curtin-Hammett Principle: A Qualitative Understanding. Resonance 2016, 21, 151-171.

78. Diccianni, J. B.; Diao, T., Mechanisms of Nickel-Catalyzed Cross-Coupling Reactions. Trends Chem. 2019, 1, 830-844.

$79 . \quad H o o k e r$, L. V.; Neufeldt, S. R., Ligation state of nickel during $\mathrm{CO}$ bond activation with monodentate phosphines. Tetrahedron 2018, 74, 6717-6725.

80. $\quad$ Entz, E. D.; Russell, J. E.; Hooker, L. V.; Neufeldt, S. R., Small Phosphine Ligands Enable Selective Oxidative Addition of $\mathrm{Ar}-\mathrm{O}$ over $\mathrm{Ar}$ $\mathrm{Cl}$ Bonds at Nickel (0). J. Am. Chem. Soc. 2020, 142, 15454-15463.

81. Amatore, C.; Bensalem, S.; Ghalem, S.; Jutand, A., Mechanism of the carbopalladation of alkynes by aryl-palladium complexes. $J$. Organomet. Chem. 2004, 689, 4642-4646.

82. Zargarian, D.; Alper, H., Palladium chloride catalyzed dicarbonylation of terminal alkynes. Organometallics 1991, 10, 2914-2921.

83. Zargarian, D.; Alper, H., Palladium-catalyzed hydrocarboxylation of alkynes with formic acid. Organometallics 1993, 12, 712-724.

84. Allen, S. R.; Beevor, R. G.; Green, M.; Norman, N. C.; Orpen, A. G.; Williams, I. D., Reactions of co-ordinated ligands. Part 33. Mononuclear $\eta^{2}$-vinyl complexes: synthesis, structure, and reactivity. $J$. Chem. Soc., Dalton Trans. 1985, 435-450.

85. Tanke, R. S.; Crabtree, R. H., Unusual activity and selectivity in alkyne hydrosilylation with an iridium catalyst stabilized by an oxygendonor ligand. J. Am. Chem. Soc. 1990, 112, 7984-7989.

86. Greaves, M. E.; Humphrey, E. L. J.; Nelson, D. J., Reactions of nickel (0) with organochlorides, organobromides, and organoiodides: mechanisms and structure/reactivity relationships. Catal. Sci. Technol. 2021, 11, 2980-2996.

87. Payard, P.-A.; Perego, L. A.; Grimaud, L.; Ciofini, I., A DFT Protocol for the Prediction of 31P NMR Chemical Shifts of Phosphine
Ligands in First-Row Transition-Metal Complexes. Organometallics 2020, 39, 3121-3130.

88. Matsubara, K.; Yamamoto, H.; Miyazaki, S.; Inatomi, T.; Nonaka, K.; Koga, Y.; Yamada, Y.; Veiros, L. F.; Kirchner, K., Dinuclear Systems in the Efficient Nickel-Catalyzed Kumada-Tamao-Corriu CrossCoupling of Aryl Halides. Organometallics 2016, 36, 255-265.

89. Christian, A. H.; Müller, P.; Monfette, S., Nickel Hydroxo Complexes as Intermediates in Nickel-Catalyzed Suzuki-Miyaura CrossCoupling. Organometallics 2014, 33, 2134-2137.

90. Payard, P.-A.; Perego, L. A.; Ciofini, I.; Grimaud, L., Taming Nickel-Catalyzed Suzuki-Miyaura Coupling: A Mechanistic Focus on Boron-to-Nickel Transmetalation. ACS Catal. 2018, 8, 4812-4823.

91. Thomas, A. A.; Zahrt, A. F.; Delaney, C. P.; Denmark, S. E., Elucidating the role of the boronic esters in the Suzuki-Miyaura reaction: Structural, kinetic, and computational investigations. J. Am. Chem. Soc 2018, 140, 4401-4416.

92. Lennox, A. J.; Lloyd-Jones, G. C., Selection of boron reagents for Suzuki-Miyaura coupling. Chem. Soc. Rev. 2014, 43, 412-443. 
TOC

Stereoconvergent and Stereodivergent Ni-Catalyzed Cross-Coupling

Data science guided HTE

